\title{
ACIDENTES DE TRÂNSITO: UMA VISÃO MÉDICO-LEGAL
}

\author{
José Carlos Macedo MONTEIRO', Raul Coelho BARRETO FILHO²
}

Monteiro, J.C.; Barreto Filho, R.C. Acidentes de trânsito: uma visão médico-legal. Saúde, Ética \& Justiça, 4(1/2):4855, 1999.

Resumo: Há muitas controvérsias sobre a redução da mortalidade em acidentes de trânsito com as imposições da lei. Foram estudados as vítimas fatais de acidente de trânsito na Bahia, que foram necropsiadas no I.M.L. "Nina Rodriguez", no período de janeiro de 1994 a junho de 1998 mediante análise dos laudos de exames cadavéricos. O número de vítimas de acidente de trânsito aumentou cerca de 10,8\%. O sexo masculino compreendeu $77 \%$ das vítimas em média. A principal faixa etária foi a de 15 a 40 anos. A lei $n^{\circ} 6.907^{9}$ que obrigava o uso do cinto de segurança em 1995 e o novo código de trânsito brasileiro ${ }^{8}$, ainda não mostraram do ponto de vista médico-legal redução no número de vítimas fatais nos acidentes de trânsito.

Unitermos: Medicina legal. Acidentes de trânsito/legislação \& jurisprudência. Acidentes de trânsito/estatística e dados numéricos/Brasil. Punição.

\section{Introdução}

$\mathrm{O}$ acidentes de trânsito, em sua grande maioria, são causados por excesso de velocidade ${ }^{9}$, estado de embriaguez do condutor, imperícia, imprudência, negligência, etc. Isto é, por desrespeito aos limites impostos pelas leis que geralmente são desconhecidos pelos condutores de veículos.

As autoridades há muitos anos vem propondo medidas legais que pudessem reduzir o número de acidentes de trânsito. Com efeito, fora estabelecido na Bahia a lei no 6.907 em 28 de setembro de 1995, que tornava obrigatório o uso do cinto de segurança nas vias urbanas de todos os seus municípios?.

Em 23 de setembro de 1997 através da lei 9.503 foi instituído o novo código de trânsito brasileiro $^{8}$, que passaria a vigorar em 22 de janeiro de 1998 com o estabelecimento da lei no 9.602.

O novo código, apresenta punições severas àqueles que desrespeitarem a lei, multas bastante altas e medidas administrativas implacáveis.

Com a implantação do novo código de trânsito

\footnotetext{
1 Acadêmico do $4^{\circ}$ ano do curso médico da Escola Baiana de Medicina e Saúde Pública.

${ }^{2}$ Médico Legista do Instituto Médico Legal Nina Rodrigues, professor assistente de medicina legal da Faculdade de Medicina da UFBA e da Escola Baiana de Medicina e Saúde Pública.

Endereço para correspondência: Rua Florianópolis, 191, Apt ${ }^{\circ}$ 501. Jardim Brasil, Barra. 40.140-320. Salvador, Bahia, Brasil.
} 
Monteiro, J.C. \& Barreto Filho, R.C. Acidentes de trânsito: uma visão médico-legal.

brasileiro, as autoridades e a sociedade em geral criaram expectativas em torno da possibilidade da redução da mortalidade no trânsito. Contudo, ainda não foram apresentados trabalhos científicos que comprovassem a eficácia das leis quanto a redução dos acidentes de trânsito.

\section{Objetivo}

O objetivo do presente estudo é analisar estatisticamente se houve redução na mortalidade do trânsito na Bahia, com a imposição das leis no 6907 do uso obrigatório do cinto de segurança e a lei no 9503 que instituiu o novo código de trânsito brasileiro.

\section{Acidentes de trânsito}

"Seria (a priori) difícil dizer da freqüência e da tendência progressiva da morte por acidentes, por ser do domínio do caso fortuito, e portanto imprevisível, se a experiência não mostrasse, pela multiplicação dos perigos da vida civilizada, outras tantas possibilidades de agravo à saúde, à integridade física e a vida do homem. De feito, o acidente dependia outrora simplesmente do acaso das forças naturais rebeldes e imprevistas tempestades, raios, inundações, naufrágios, incêndios - hoje, além destas, com abundância, a civilização gravou pesadamente a freqüência, devido aos instrumentos de progresso e de conforto, transformados eventualmente em meio de morte'4.

O professor Afrânio Peixoto ${ }^{4}$ naquela época, já havia pensado em quão grande seriam as proporções das lesões à saúde do homem e a morbidade que surgiria determinada pelo progresso e advento da tecnologia que ao mesmo tempo que proporcionou conforto, trouxe ao lado a morte como freio para a vaidade do homem e como incremento para os acidentes que deixaram de ser fortuitos para serem comuns ${ }^{9}$.

É importante conhecer as causas e circunstâncias que rodeiam um acidente de trânsito. O seu estudo estatístico detalhado é fundamental para que se possa exercer as medidas de segurança capazes de reduzir sua morbidade ${ }^{1}$. As causas mais freqüentes são o estado de alcoolismo do condutor do veículo, excesso de velocidade, imperícia, imprudência, negligência, uso de estimulantes, etc.

$\mathrm{Na}$ Bahia, o estabelecimento da lei de № 6907 de 28 de setembro de 1995 determinou a obrigatoriedade do uso do cinto de segurança ${ }^{9}$ nas vias urbanas de todos os seus municípios marcando assim a história dos acidentes de trânsito com uma lei que em tese seria importante para redução das vítimas fatais. A obrigatoriedade do uso de cinto de segurança sempre foi discutida por estudiosos do trânsito que consideram o uso deste importante para a redução da morbidade.

A falta de conhecimento das vias, desrespeito às sinalizações, ausência de distância de segurança, ou seja, a imprudência e a negligência, além da imperícia no ato de dirigir um veículo, podem justificar muitos acidentes de trânsito ${ }^{7}$. $O$ corpo não é capaz de absorver toda energia do impacto se esta não é distribuída, e sim localizada em uma pequena área ${ }^{3}$. Se o corpo humano é projetado, a gravidade das lesões é capaz de aumentar cerca de cinco vezes ${ }^{7}$. Dessa forma, justificam-se as severidade das lesões nas vítimas 
Monteiro, J.C. \& Barreto Filho, R.C. Acidentes de trânsito: uma visão médico-legal.

de acidente de trânsito que não usam o cinto de segurança ${ }^{9}$.

\section{Métodos}

\section{Critérios de inclusão}

Foram estudados as vítimas fatais de acidente de trânsito na Bahia, que foram necropsiadas no I.M.L. "Nina Rodriguez", no período de janeiro de 1994 a junho de 1998, mediante análise dos laudos de exame cadavéricos das mesmas.

\section{Critérios de exclusão}

Foram consideradas inelegíveis para o estudo as vítimas de acidente de trânsito:

-não fatais;

-fatais, que não foram necrospsiadas no I.M.L "Nina Rodriguez".

\section{Desenho de estudo}

O protocolo utilizado para arquivo de dados foi formado por um questionário com informações relevantes, tais como as seguintes variáveis: nome, idade, sexo, semestre e ano do acidente.

Os exames complementares, tais como: dosagem de álcool e de substâncias entorpecentes no sangue não foram considerados neste estudo.

\section{Análise estatística}

Os dados do presente estudo foram inseridos em um banco de dados e analisados pelo programa estatístico SPSS for Windows (Release 6.1- Standard version). As variáveis categóricas foram analisadas pelos testes do Qui-quadrado. Foi estudado separadamente os seguintes itens do questionário:
1. sexo mais acometido;

2. vítimas por faixa etária;

3. total de vítimas: ano, semestre.

\section{Resultados}

A Tabela 1 mostra a prevalência das vítimas fatais de acidentes de trânsito nos anos de 1994, 1995, 1996, 1997, 1998*, no que concerne os sexos.

Podemos observar uma prevalência absoluta do sexo masculino, correspondendo uma média de $77 \%$ das vítimas.

Tabela 1 - Vítimas fatais de acidente de trânsito

\begin{tabular}{c|c|c|cc}
\hline Ano & Masculino & Feminino & \multicolumn{2}{|c}{$\%$} \\
\hline \hline 1994 & 587 & 166 & $\mathrm{M}=78 \%$ & $\mathrm{~F}=22 \%$ \\
1995 & 606 & 205 & $\mathrm{M}=75 \%$ & $\mathrm{~F}=25 \%$ \\
1996 & 635 & 175 & $\mathrm{M}=78 \%$ & $\mathrm{~F}=22 \%$ \\
1997 & 659 & 181 & $\mathrm{M}=79 \%$ & $\mathrm{~F}=21 \%$ \\
$1998^{\star}$ & 299 & 95 & $\mathrm{M}=76 \%$ & $\mathrm{~F}=24 \%$ \\
\hline
\end{tabular}

* Dados apurados até 30 de junho

No Gráfico 1 observa-se que a faixa etária entre 16 e 30 anos compreendeu cerca de $30 \%$ das vítimas fatais em 1994.

Gráfico 1 - Número de vítimas por faixa etária em 1994

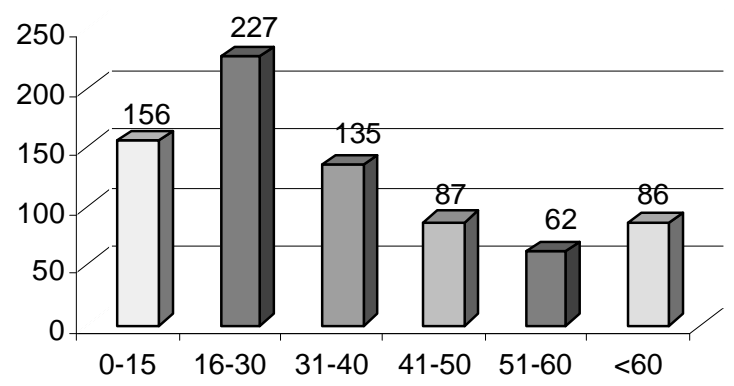


Monteiro, J.C. \& Barreto Filho, R.C. Acidentes de trânsito: uma visão médico-legal.

O Gráfico 2 mostra as vítimas segundo faixa etária em 1995.

Gráfico 2 - Número de vítimas por faixa etária em 1995

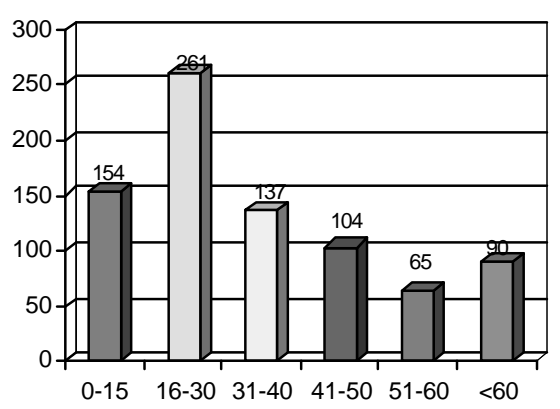

O Gráfico 3 mostra as vítimas por faixa etária em 1996 com dados relevantes na avaliação da principal faixa etária acometida já que com relação a 1995, houve um aumento considerável nas vítimas entre 0 e 15 anos e uma queda na faixa etária entre 16 e 30 anos.

Gráfico 3 - Número por faixa etária em 1996

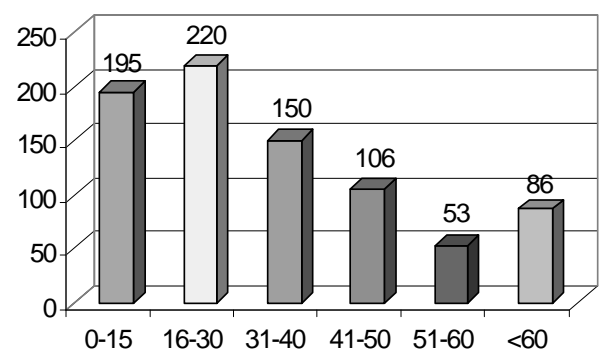

O Gráfico 4 demonstra a prevalência das vítimas segundo as faixas etárias mais acometidas em 1997.

\section{Gráfico 4 - Número de prevalência das vítimas} segundo faixa etária

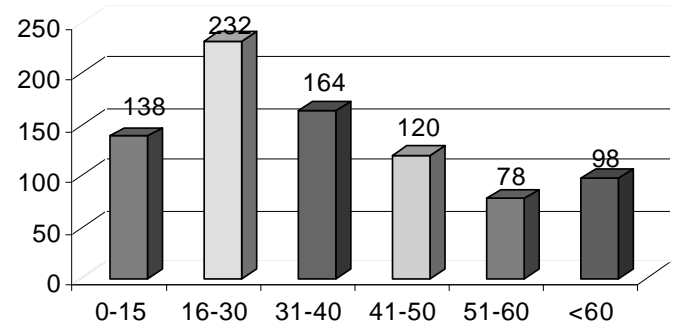

O Gráfico 5 mostra uma incidência cerca de $12 \%$ maior de vítimas na faixa etária entre 16 a 30 anos em relação a faixa etária de 31 a 40.

Gráfico 5 - Número de vítimas por faixa etária em 1998

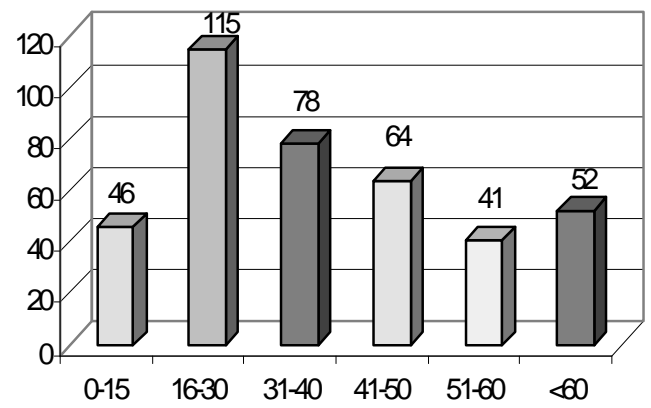

A Tabela 2 mostra o número total das vítimas fatais de acidente de trânsito que foram necropsiadas no I.M.L. "Nina Rodriguez" no período de estudo.

Tabela 2 - Número de vítimas fatais de acidente de trânsito necropsiadas no I.M.L. "Nina Rodrigues"

\begin{tabular}{c|c}
\hline Ano & Total de vítimas \\
\hline \hline 1994 & 753 \\
1995 & 811 \\
1996 & 810 \\
1997 & 840 \\
1998 & 394 \\
\hline
\end{tabular}

O Gráfico 6 mostra os resultados apresentados na Tabela 2 em colunas, exceto a coluna do ano de 1998 que está representando uma estimativa do autor.

Gráfico 6 - Total de vítimas fatais de acidentes de trânsito - 1994-98

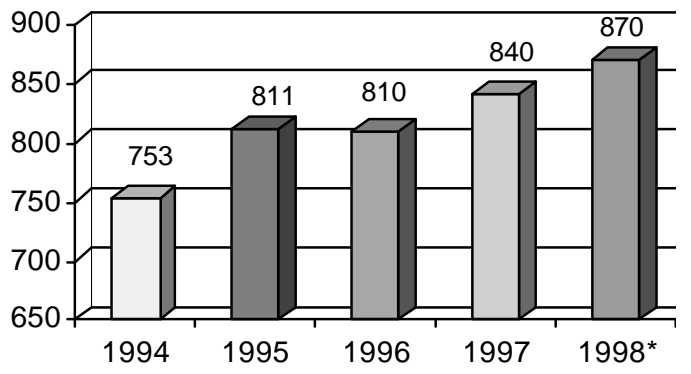


Monteiro, J.C. \& Barreto Filho, R.C. Acidentes de trânsito: uma visão médico-legal.

O Gráfico 7 mostra curva da variação do número de vítimas fatais de acidente de trânsito entre 1994 e $1998^{*}$

Gráfico 7 - Curva de variação - número de vítimas fatais

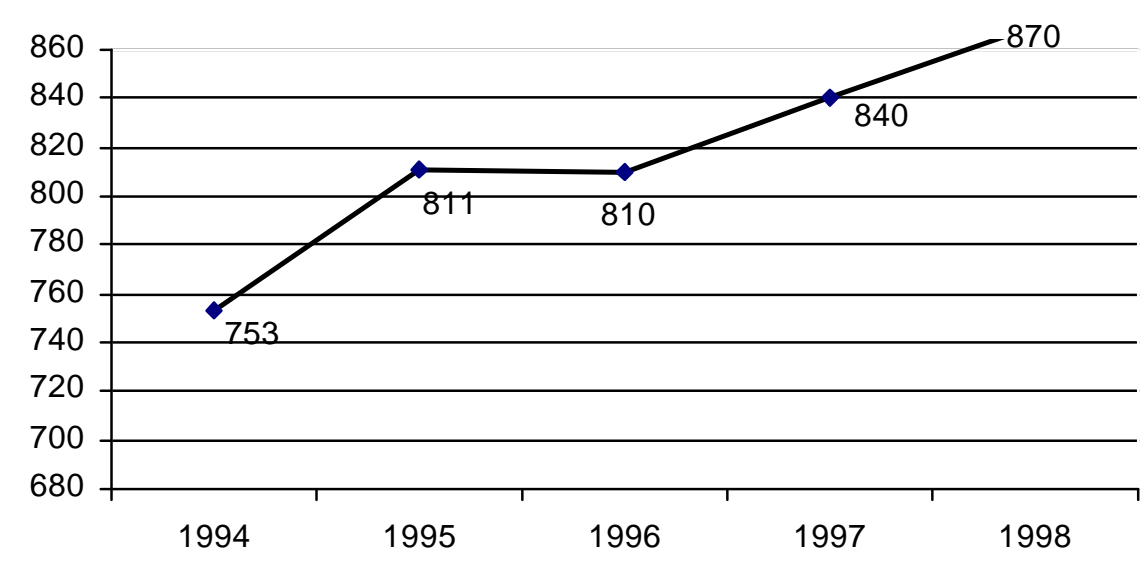

O Gráfico 8 a seguir mostra em colunas o número total de vítimas do primeiro semestre nos anos de 1994 a 1998.

Gráfico 8 - Número de vítimas do 1ํ semestre

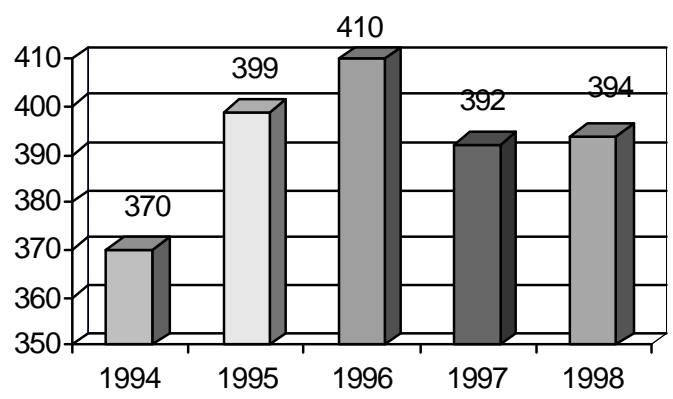

O Gráfico 9 mostra o número total de vítimas do segundo semestre dos anos de 1994 a 1998*.

\section{Gráfico 9 - Número de vítimas do $2^{\circ}$ semestre}

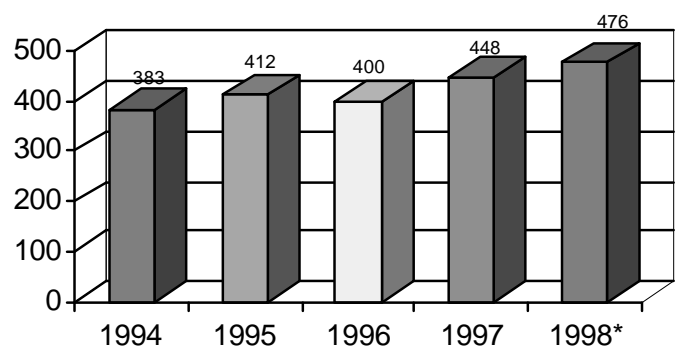

\section{Discussão}

\section{Sexo mais acometido}

Os resultados obtidos e demonstrados pelos gráficos mostram uma prevalência no número de mortos do sexo masculino. Portanto, diante desses dados é importante refletir a questão da mortalidade masculina como sendo algo de extrema sensibilidade, principalmente porque dados científicos comprovam um maior nascimento de indivíduos do sexo feminino em relação ao masculino. Isto significa que o aumento progressivo das mortes masculinas em acidentes de trânsito embora represente uma pequena parcela das mortes em geral, pode resultar numa queda progressiva da população masculina que seria desastrosa para equilíbrio da humanidade. É necessário frisar que boa parte das vítimas fatais no trânsito do sexo feminino não eram condutoras do veículo, ou seja, eram passageiros de um veículo mal conduzido por homens imprudentes que causaram essas mortes. 
Monteiro, J.C. \& Barreto Filho, R.C. Acidentes de trânsito: uma visão médico-legal.

O comentário sobre a mortalidade no trânsito no que diz respeito ao sexo, não poderia deixar de abordar aspectos gerais sobre as diferenças entre homens e mulheres já que está inerente dentro desta reflexão a principal causa da mortalidade diferencial entre os sexos.

O conceito sexo não pode ser expresso apenas em termos morfológicos e funcionais, já que na definição do sexo intervêm fatores como a genética, isto é, o fenótipo sexual depende de mecanismos fisiológicos, como hormônios, responsáveis pelos aferidos aspectos². É preciso estudar e compreender os fatores culturais e psicológicos que circundam o ser desde o seu nascimento para compreender, a causa de um problema tão significativo como os índices da mortalidade no sexo masculino no trânsito ou a variação anual dentro da estatística do sexo feminino ${ }^{9}$. O mundo cultural é um sistema de significados já estabelecidos por outros, de modo que, ao nascer a criança encontra um mundo de valores já dados, onde ela vai se situar. A língua que aprende, o m odo de agir, as relações fam libres, tudo enfm se acha codificado'. Na nossa sociedade podemos notar a visão estereotipada da masculinidade, a qual vê com complacência o choro feminino e o recrimina no homem. Tendo em vista esses aspectos, podemos concluir que a negligência, o alcoolismo, os impulsos desenfreados dos homens se fundamenta na onipotência pré-determinada por uma cultura que o circunda e lhe faz vítima de seus próprios vícios. Portanto é preciso que a população masculina seja esclarecida de forma a evitar os acidentes de trânsito e assim tentar reduzir a mortalidade no trânsito.

\section{Vítimas por faixa etária}

A mortalidade no trânsito segundo a faixa etária, revelou dados preocupantes. Em todos os anos de estudo a principal faixa etária foi de 16 a 30 anos. Nos anos de 1994 a 1996 a segunda faixa etária mais acometida foi a de 0 a 15 anos, enquanto que em 1997 e no primeiro semestre de 1998, a segunda faixa etária mais acometida foi a de 31 a 40 anos. A análise geral dos gráficos das vítimas por faixa etária, nos permite concluir que no período de estudo a principal faixa etária foi a de 0 a 40 anos, representando cerca de $66 \%$ do número total das vítimas de acidentes de trânsito nesse período. É importante ressaltar sobretudo que a grande maioria das vítimas da faixa etária entre 0 e 15 anos de idade eram passageiros. As vítimas acima de 15 anos e menores de 18 anos, que se enquadraram no grupo principal das vítimas do trânsito, cerca de $57 \%$ eram condutores sem carteira nacional de habilitação.

A constatação de dados tão relevantes com relação as faixas etárias das vítimas de acidentes de trânsito, mostra a necessidade urgente de serem implantados serviços de orientação aos jovens motoristas, assim como campanhas nacionais de educação no trânsito, pois não basta o estabelecimento de leis que imponham regras no trânsito se os condutores de veículo não tiverem uma formação educacional que possa gerar uma consciência sobre os agravos à sociedade que são causados pelo desrespeito às leis.

\section{Total de vítimas: ano, semestre}

Os dados revelados nesta etapa do nosso estudo, evidenciam controvérsias no que diz respeito a eficácia das imposições das leis na redução da mortalidade no trânsito. Como foi 
Monteiro, J.C. \& Barreto Filho, R.C. Acidentes de trânsito: uma visão médico-legal.

mostrado na sessão anterior, do ano de 1994 até o ano de 1997 tivemos um aumento de 11\% no total das vítimas de acidentes de trânsito. Em 28 de setembro de 1995 foi estabelecido a lei que obrigava o uso do cinto de segurança na Bahil. Àquela época a implantação dessa lei representou um marco legal que buscava a redução da mortalidade nos acidentes de trânsito. Contudo os resultados apresentados aqui neste estudo mostrou que essa lei do ponto de vista médicolegal não representou um fator decisivo na redução da mortalidade no trânsito. A análise estatística segundo o perfil semestral da mortalidade no trânsito, nos fez perceber um aumento gradual no total das vítimas de 1994 a 1995. Entre os anos de 1995 e 1996 observamos um certo equilíbrio, mas a partir de 1996 o aumento passou a ser de $3,6 \%$ ao ano. Portanto, no ano de 1998 provavelmente não será diferente, pois seu número de vítimas fatais no primeiro semestre é superior ao de 1997.

Mais uma vez se faz necessário relembrar um marco memorável, da legislação do trânsito. Em 22 de janeiro de 1998, entrou em vigor o novo código de trânsito brasileiro8. Esse código, surgiu com o intuito de reduzir os acidentes de trânsito, mediante regras administrativas e penais bastante severas. Não obstante, o presente estudo revelou que no primeiro semestre de 1998 tivemos uma mortalidade no trânsito superior a de 1997. Logo, pode-se perceber que a curto prazo o novo código ainda não demonstrou eficácia nesse aspecto. Caso a tendência de aumento gradual do total das vítimas fatais de acidentes de trânsito se mantenha, em 1998 teremos mais vítimas fatais de acidentes de trânsito que em todos os anos anteriores.

\section{Conclusão}

Os acidentes de trânsito no mundo moderno encontraram condições favoráveis para o seu incremento ${ }^{1}$. A quantidade crescente de acidentes e vítimas de trânsito que ocorrem na Bahia, nada mais é do que fruto da falta de respeito aos limites da natureza, que parecem ser desconhecidos pelos condutores de veículo.

Segundo Buarque ${ }^{10}$, acidente é um acontecimento casual, imprevisto, de que resulta ferimento, dano, etc. Uma breve análise do significado de acidente apresentado pelo famoso dicionário, nos permite discordar desse conceito quando estiver relacionado ao trânsito. Pois, os acidentes de trânsito deixaram há muitos anos de serem casuais, ou fortuitos. Já que é do conhecimento geral que abuso de álcool, excesso de velocidade, negligência, imprudência e imperícia no trânsito resultam em acidente. Não sendo evidentemente necessário de que todos esses fatores estejam associados.

Os dados apresentados neste estudo médicolegal sobre acidentes de trânsito, evidenciou a necessidade de serem implantados serviços de orientação e educação no trânsito, para que as imposições da lei possam ser cumpridas à risca, tornando eficazes as leis do trânsito no combate aos acidentes de trânsito. Além disso, o presente estudo demonstrou que a lei $n^{\circ} 6907^{9}$ que obrigava o uso do cinto de segurança na Bahia e o novo código de trânsito brasileiro ${ }^{8}$ ainda não mostraram do ponto de vista médico-legal redução no número de vítimas fatais nos acidentes de trânsito. 
Monteiro, J.C. \& Barreto Filho, R.C. Acidentes de trânsito: uma visão médico-legal.

Monteiro, J.C.; Barreto Filho, R.C. Traffic accidents: forensic medical view. Saúde, Ética \& Justiça, 4(1/2):48-55, 1999.

Abstract: Background. There are many controversys about the reduction of the mortality in traffic accidents caused by laws order. Were studied the factual victims of traffic accidents in Bahia, that were skill necropsy at the forensic medical Institute "Nina Rodriguez", in the period from 1994 january to 1998 june, by analysis in the cadaveric award examination. The number of traffic victims increase $10,8 \%$. The male compreended $77 \%$ of the victims. The principal age band were 15 to 40 years old. The law 6.907 that obrigate wering the safety belt in 1995 and the new brasilian traffic code, don't show by the forensic medical view reduction in the frequency of factual victims in traffic accidents.

Keywords : Forensic medicine. Accidents, traffic/legislarion \& jurisprudence. Accidents, traffic/statistics \& numerical data/Brazil.

Agradecimentos: À Prof ${ }^{a}$ Dra $^{a}$. Maria Theresa de Medeiros Pacheco, Diretora do Departamento de Polícia Técnica do Estado da Bahia, pela gratificante experiência de ser seu discípulo.

\section{Referências Bibliográficas}

1. Fávero, F. Medicina legal. São Paulo, Martins, 1966.

2. Arbenz, G.O. Medicina legal e antropologia forense . Rio de Janeiro, 19...

3. França, G.V. Medicina legal. Rio de Janeiro, Guanabara Koogan, 1994.

4. Peixoto, A. Elementos da medicina legal. Rio de Janeiro, 1914

5. Severino, A.J. Metodologia do trabalho científico. São Paulo, Cortez, 1995.

6. Spector, N. Manual para redação de teses, dissertações e projetos de pesquisa. Rio de Janeiro, Guanabara Koogan, 1997.
7. Alcântara, H.R. Perícia médica judicial. Rio de Janeiro, Guanabara Dois, 1987.

8. Lazzari, C.F.; Witter, I.R. Nova coletânea de legislação do trânsito. Porto Alegre, Sagra Luzzatto, 1998.

9. Monteiro, J.C.M.; Lima Filho; J.A.; Oda, V.S. Cinto de segurança - estudo da mortalidade. In: Jornada de Medicina Legal do Nordeste, 2., Porto Seguro, 1997.

10. Ferreira, A.B.H. Minidicionário da língua portuguesa. Rio de Janeiro, Nova Fronteira, 1985.

11. Aranha, M.A.; Martins, M.P. Filosofando introdução à filosofia. São Paulo, Moderna, 1988. 